\title{
PERCEPÇÃO DOS BOMBEIROS PARANAENSES SOBRE A CAPACITAÇÃO TÉCNICA NECESSÁRIA ÀS OPERAÇÕES DE RESGATE EM ENCHENTES
}

\section{RESUMO}

\author{
Igor Luiz Piotrovski ${ }^{1}$ \\ Cristiano Luis Medina ${ }^{2}$ \\ Sandro Cesar Martins dos Santos ${ }^{3}$
}

Este artigo tem como tema os resgates em águas correntes e enchentes. Trata da importância do resgatista proceder adequadamente em ocorrências de águas rápidas, como também em enchentes, pois, o resgate em correnteza exige técnicas complexas e nem sempre os bombeiros têm formação ampla. $O$ objetivo foi investigar a importância do conhecimento de técnicas de resgates em águas correntes dos bombeiros do Paraná e suas percepções quanto a essa capacitação específica, entre outras particularidades da formação para melhor socorrer em águas correntes e enchentes. Justifica essa pesquisa, porque se trata de um assunto importante, não somente no Estado do Paraná, como em outros Estados do Brasil, principalmente em regiões litorâneas, pois cada vez mais as enchentes acontecem, necessitando assim de conhecimento e preparo técnico desses profissionais. A conduta adequada numa situação conflituosa de enchentes pode ser problemática por vários fatores, entre eles: a falta de equipe específica para essa conduta, também o fato de não se ter vivenciado situações de enchentes, ou ter conhecimento teórico e superficial dos procedimentos. Quanto à metodologia, se trata de uma pesquisa qualitativa-descritiva, onde foi aplicado um questionário investigativo para verificar a percepção dos bombeiros quanto a formação específica no resgate em águas correntes e enchentes. Neste contexto, o resgate em estudo é um dos mais perigosos, assim é necessário melhor preparação de equipes de resgatistas, para que cada vez mais, sejam feitos os resgates com sucesso e amenizados os números de vítimas.

Palavras-chave: Resgates. Águas correntes. Enchentes. Preparação do resgatista.

\footnotetext{
${ }^{1}$ Sargento Bombeiro Militar, Polícia Militar do Estado do Paraná

${ }^{2}$ Sargento Bombeiro Militar, Polícia Militar do Estado do Paraná.

${ }^{3}$ Sargento Bombeiro Militar, Polícia Militar do Estado do Paraná.
} 


\title{
PARANÁ STATE'S FIREFIGHTERS PERCEPTION ON TECHNICAL TRAINING REQUIRED TO RESCUE OPERATIONS IN FLOODS
}

\begin{abstract}
This article has as its theme the rescues in running water and floods. It's about the importance of the rescuer to proceed rightly in occurrences of rapid waters as well as floodings, as the rescue in running waters requires complex techniques and not always the firefighters have extensive training. The general objective was to investigate the importance of technical knowledge on rescues in running waters of Paraná State Firefighters and their perceptions about this specific training. This research is justified, because it is an important subject, not only on the Paraná State, as in other Brazilian states especially in coastal regions because the flood happens there frequently requiring knowledge and technical preparation of these professionals. Proper conduct in a conflict situation of floods can be problematic for several factors, , such as: do not have specific team, had not experienced flood situations, or the superficial theoretical knowledge. As for the methodology, it is a qualitative descriptive study, which was applied an investigative questionnaire to verify the perception of fire as specific training in rescue in running water and floods. In this context, the running water rescue is one of the most dangerous, so it is necessary to better prepare teams of rescuers, for the rescues to be even more successful and minimize the number of victims.
\end{abstract}

Keywords: Rescues. Running waters. Floods. Rescuers preparation.

Artigo recebido em 27/04/16 e Aceito em 16/11/16. 


\section{INTRODUÇÃO}

No Brasil o processo de urbanização ocorreu de forma intensa e irregular. Em muitas cidades brasileiras viver com qualidade não é privilégio de todos, levando dessa forma, parte da população menos favorecida e pouco informada, a ocupar áreas de risco, que apresentam perigos a vida e que são impróprias para moradia (ANGULO, 2000).

Além da questão da urbanização, em muitos Estados do Brasil têm-se outras condições socioambientais que influenciam na ocorrência de enchentes como é o caso de localidades próximas de rios ou litorâneas, onde o agravante está nos ciclos naturais da erosão/sedimentação das praias, como também a erosão provocada pelas águas de escoamento superficial e os escorregamentos de diversos tipos nas encostas dos morros, comprometendo seriamente a infraestrutura existente (ALVES, 2012).

A associação desses vários fatores, juntamente às questões ambientais e desastres naturais, conforme descreve Costa (2011), tem se demonstrado um assunto muito comentado atualmente, em diferentes áreas do conhecimento.

A justificativa que impulsionou essa pesquisa, é exatamente nessa questão de que se trata de um assunto importante, não somente no Estado do Paraná, como em outros Estados do Brasil, principalmente em regiões litorâneas, pois cada vez mais as enchentes acontecem, necessitando assim de conhecimento e preparo técnico desses profissionais.

Segundo Segerstrom et al $(2002$, p. 5) "pode ser que neste século o resgate em água corrente seja a área de resgate técnico que tenha o maior crescimento dinâmico, porque mesmo que a tecnologia esteja crescendo, os problemas crescem mais rápido." Portanto, águas correntes apresentam-se 
Revista Científica do Corpo de Bombeiros Militar de Pernambuco

Seção 1 - Artigos Técnico Científicos

Artigo publicado no Vol.03 №06 - Edição de JAN a JUN 2017 - ISSN 2359-4829

Versão on-line disponível em: http://www.revistaflammae.com

como um dos grandes perigos encontrados hoje, em enchentes urbanas ou em acidentes em rios.

Com uma área de $6.057 \mathrm{~km}^{2}$ o Litoral do Paraná é constituído por sete municípios, sendo estes: Antonina, Guaraqueçaba, Guaratuba, Matinhos, Morretes, Paranaguá e Pontal do Paraná (ALVES et al, 2012).

De acordo com o geólogo paranaense Renato Eugênio Lima, professor da UFPR e Secretário de Meio Ambiente da Prefeitura Municipal de Curitiba/PR, desastres ambientais, tais como o ocorrido no Litoral do Paraná em março de 2011, já haviam sido previstos anteriormente por estudiosos, em particular da Universidade Federal do Paraná (LIMA; MALUF, 2011).

Além do mais, no início da década de 1980, Bigarella (1986) fazia diversas denúncias sobre as consequências da devastação da Mata Atlântica, como também a necessidade de um olhar atento das autoridades em relação à Serra do Mar e a degradação florestal no Estado do Paraná. Consequentemente, a problemática acentuou-se com as chuvas em abundância e os deslizamentos ocorridos na região em 11 de março de 2011 foi um fato marcante na vida da população litorânea.

Desde então, muitas questões passaram a ser repensadas, voltandose um olhar para os desastres naturais, enchentes e alagamentos ocorridos no litoral. Pois, têm sido cada vez mais recorrentes no Brasil e no mundo (COSTA, 2011).

Assim, devido à incidência de enchentes na atualidade, e das problemáticas relacionadas a esses resgates e salvamentos, é importante uma equipe de resgatistas bem preparada, com técnicas e procedimentos adequados (AMBROSI, 2010).

Nesse contexto, a pesquisa objetivou investigar a importância do conhecimento de técnicas de resgates em águas correntes dos bombeiros do Paraná e suas percepções quanto a essa capacitação, verificando assim sobre a formação profissional dos sujeitos da pesquisa o preparo para o resgate em 
Revista Científica do Corpo de Bombeiros Militar de Pernambuco

Seção 1 - Artigos Técnico Científicos

Artigo publicado no Vol.03 №06 - Edição de JAN a JUN 2017 - ISSN 2359-4829

Versão on-line disponível em: http://www.revistaflammae.com

estudo . Também se ateve em apresentar os conhecimentos teóricos, entre outras particularidades que orientam os resgates em enchentes e águas correntes.

Em época de grandes e constantes catástrofes naturais, a formação do bombeiro militar deve permanecer em constante transformação e adaptação. Neste contexto, os cursos de formação e aperfeiçoamento devem ser constantemente atualizados com as mais eficientes táticas e modernas técnicas (COSTA, 2011).

\subsection{Enchentes e Águas Correntes}

Inicialmente é necessária uma compreensão a cerca das enchentes, para uma melhor execução dos procedimentos e operações nestas situações, uma vez que, entre as diversas consequências associadas a esse desastre natural, está a perda de vidas, destruição de moradias e abrigos, perda de bens na indústria, comércio e agricultura, como também paralização das atividades econômicas e de serviços públicos de abastecimento de água, energia, sistemas de comunicação e transportes, entre outras.

Ramos et al (2011), abordam que as enchentes têm o maior potencial de danos entre todas as catástrofes naturais em todo o mundo. Uma vez que o número de eventos vem aumentando nos últimos anos, devido ao crescimento urbano e populacional, que na maioria das cidades ocorre de maneira desordenada e sem planejamento.

Angulo (2000) especifica que as praias do Paraná, enfrentam problemas decorrentes de uma ocupação inadequada, tais problemas, cíclicos e sazonais, ressurgem no verão, quando se intensifica a perspectiva de utilização das praias desencadeando novos problemas de caráter físicoterritorial, urbanístico, ambiental e socioeconômico.

Segundo o referido autor, nas fases de ciclos erosivos, a areia é retirada do mar, pondo em risco ou destruindo obras construídas nas 
proximidades. muito próximas a ele. Outros problemas são a erosão provocada pelas águas de escoamento superficial e os escorregamentos de diversos tipos nas encostas dos morros, que também comprometem seriamente a infraestrutura, além do mais, em épocas de tormenta, as fortes chuvas fornecem grandes caudais de água a esses rios da região, causando diferentes danos às obras com deságues mal dimensionados, como o caso do calçadão da Praia de Guaratuba (ANGULO, 2000).

Assim, as questões estruturais e de movimentação da região litorânea do Paraná, necessitam de uma atenção, tanto para medidas de prevenção em casos de desastres naturais, como também, em questão de conhecimento para casos de resgates em situações de risco.

Silva (2012), explica que existem muitas questões a se considerar, diante do resgate em inundações e em águas correntes, também chamado de águas rápidas, como as Diretrizes de Procedimentos Operacionais Padrões (DtzOpP), para qualificações dos profissionais resgatistas, para que estes desenvolvam cada vez mais, habilidade e tempo resposta a cada ocorrência de salvamento em águas rápidas.

Essas questões, se aplicadas aos treinamentos, poderão proporcionar inestimável ganho de qualidade nos serviços prestados à população, permitindo o emprego das melhores técnicas, com menor risco para vítimas e para os próprios bombeiros (SILVA, 2012).

Com base no Manual de Salvamento Aquático (Msaq) (2010, p. 40): “ [...] a enchente é compreendida como uma inundação, [...] ocorrendo um aumento considerável do volume das águas a serem escoadas por rios, riachos e córregos, geralmente do mês de dezembro ao mês de março".

Os fatores agravantes de uma enchente são muito distintos, dependendo de condições geográficas, sociais e estruturais peculiares. Assim, quando uma equipe de socorristas é formada para prestar este tipo de socorro, 
Revista Científica do Corpo de Bombeiros Militar de Pernambuco

Seção 1 - Artigos Técnico Científicos

Artigo publicado no Vol.03 №06 - Edição de JAN a JUN 2017 - ISSN 2359-4829

Versão on-line disponível em: http://www.revistaflammae.com

é preciso conhecer tais fatores de acordo com a região, para que possa além de socorrer, garantir a própria segurança (SEGERSTROM et al, 2002).

Sendo assim, O resgatista é treinado para ter em mente que, quando está prestando o socorro, sua segurança vem em primeiro lugar, seguida da segurança da equipe, e por fim da vítima (AMBROSI, 2010).

Logo, como está descrito na Sphereproject/Carta Humanitária (2004, site), existem requisitos básicos que devem estar presentes em todas as ações de defesa à vida, os quais conferem dignidade àqueles que são afetados por catástrofes ou conflitos.

Além dos requisitos básicos, há um arsenal de ações de resgate, necessárias de serem refletidas diante de enchentes ou desastres naturais, como: busca, salvamento, resgate de feridos, desaparecidos, entre outras, cada uma com sua particularidade.

Deste modo, cada município deve promover/oportunizar a especialização de sua equipe de busca e salvamento, considerando os desastres de maior prevalência na área apoiada. Com relação às enchentes, na equipe técnica devem encontrar-se desde pessoal capacitado, equipamentos de proteção individual, até materiais para corte, sucção, escavação, mergulho, como também meios de comunicação e transporte (viaturas terrestres, aeronaves, embarcações de superfície e submarinas adequadamente equipadas e tripuladas, entre outros) (CASTRO, 1999).

Considerando a importância da equipe técnica, compreende-se que somente resgatistas treinados deveriam trabalhar dentro da água ou dentro da área de $3 \mathrm{~m}$ da margem.

Assim, a eficiência de um resgate ou o número de vidas a serem salvas, depende muito da prontidão da equipe e do modo como os fatos são desencadeados, em especial dos conhecimentos referentes às águas rápidas, entre outras particularidades das correntes. "A busca é tanto uma ciência como 
Revista Científica do Corpo de Bombeiros Militar de Pernambuco

Seção 1 - Artigos Técnico Científicos

Artigo publicado no Vol.03 №06 - Edição de JAN a JUN 2017 - ISSN 2359-4829

Versão on-line disponível em: http://www.revistaflammae.com

uma arte e deve ser apropriadamente gerenciada" (SEGERSTROM, 2002, p. 39).

Segundo Silva (2012) a corrente remete a um movimento das águas de um rio, que pode ser: descendentes (no sentido do rio), contrárias e até indefinidas, tudo dependendo da formação do leito e das margens. Enquanto a turbulência, acontece quando a corrente principal, em desnível, encontra obstáculos e passa por eles os tipos de corrente são variados:

Dentro desse contexto, Silva (2012), descreve ainda, sobre a corrente laminar: a qual é suave e sem obstáculos, assim, a água se movimenta mais rápido no centro do que no fundo e nas margens. Já o fluxo helicoidal (movimento da água de forma circular que ocorre contra a margem do rio em direção ao fluxo laminar central) pode levar os nadadores de volta a correnteza principal, especialmente em condições de rio cheio.

Compreende-se que muitos fatores influenciam na força da água, como por exemplo: o volume de água, os desníveis e a velocidade da correnteza. Pois, consequentemente, a medida que a força da água é aumentada, velocidade e volume também são. Portanto, se a velocidade da água vem em dobro, a pressão sobre os objetos submersos aumenta quatro vezes mais (ARAUJO, 2002; COSTA 2011).

Há de se ter uma atenção redobrada, com correntes helicoidais que "são formadas quando a corrente segue da margem até se chocar com a corrente principal e retorna por baixo" (SILVA, 2012, p. 4). Neste tipo de corrente especificamente, é muito difícil nadar os últimos metros, próximos a margem.

Quanto aos redemoinhos, podem ocorrer em lagos e em rios, mas não na mesma proporção em que ocorrem nos mares. "Um redemoinho segura uma vítima ou um objeto em um local fixo por um longo período de tempo em razão das forças contrárias ao deslocamento natural das águas. Este tipo de fluxo também pode criar um buraco "(MACHADO, 2001, p. 50). 
Revista Científica do Corpo de Bombeiros Militar de Pernambuco

Seção 1 - Artigos Técnico Científicos

Artigo publicado no Vol.03 №06 - Edição de JAN a JUN 2017 - ISSN 2359-4829

Versão on-line disponível em: http://www.revistaflammae.com

Dessa forma, somente com treinamento adequado pode se submeter à busca e salvamento em situações de águas bravas, principalmente em enchentes de localidades litorâneas, onde há a previsão de correntes diferenciadas, como também redemoinhos e obstáculos (AMBROSI, 2010).

Schonër (2011, p.14) descreve sobre a importância desse conhecimento das correntes de águas juntamente com a questão da avaliação dos riscos em corredeiras: essa "capacidade de entender tudo que acontece nas corredeiras e correntezas, na superfície, abaixo dela, reconhecer formas de correntezas e obstáculos, como evitar ou usá-las chamamos de ler a água".

O Manual técnico de salvamento em enchentes de São Paulo complementa explicando que "em uma enchente ou em um rio a água está se movimentando para baixo e com velocidade. Tal fato dificulta muito as operações de salvamento" (CORPO DE BOMBEIROS MILITAR DO ESTADO DE SÃO PAULO, 2006, p. 45).

Compreende-se a grande possibilidade de a água movimentar-se aceleradamente por baixo puxando as vítimas e tudo mais que estiver junto.

\subsection{Procedimentos Adequados para Entrar em Água Corrente}

O resgate em água exige, como em todas as situações de emergência, um bom gerenciamento, através de uma comunicação e execução de segurança. Nesse contexto, antes de qualquer procedimento de entrada na água precisa-se identificar o sujeito de busca, o que pode parecer muito obvio, entretanto, por meio de entrevistas e busca de dados na comunidade afetada, evita-se a "busca bastarda" (sem vítimas). Outra questão antecedente é a determinação se possível, do último ponto visto (UPV) ou último ponto conhecido (UPC), para delimitar a área de busca e separá-la de toda a área possivelmente afetada pela enchente (SEGERSTROM et al, 2002). 
Costa (2011) discorre sobre os procedimentos ao entrar em águas bravas, delimitando-os em: natação agressiva ou ofensiva, natação básica ou defensiva. Sendo a primeira correspondente à travessia de uma correnteza forte e profunda, usando a técnica "isca viva" ou atravessar um rio nadando com uma corda, ou seja, o nadador nada forte o estilo crawl ou livre, visando chegar até a vitima. Enquanto a segunda, está relacionada à possibilidade de um membro da equipe de resgate se transformar em vítima adicional. Nisto, para atravessar obstáculos rasos deverá virar de barriga para cima e colocar as duas pernas no sentido da corrente. Se estiver usando pé-de-pato, isso ajudará a ficar plano e os pés de pato subirão para superfície, enquanto o nadador está flutuando.

Silva (2012), explica sobre os procedimentos para entrar em água corrente considerando-se: avaliação da situação, dispositivo de flutuabilidade pessoal, águas rasas, regra de redemoinho seguro, águas profundas.

Tem-se inicialmente que avaliar a situação combinando os componentes da avaliação, como por exemplo: coleta de dados ou de probabilidades, tomar decisões informadas e executar planos válidos, permitindo um ambiente mais seguro para todos os envolvidos. A análise/benefício só pode ser realizada quando os perigos forem avaliados e houver a visualização do que é necessário para o resgate (SILVA, 2012).

A continuidade dessa análise, acontece sempre através do uso de um dispositivo de flutuabilidade, e nesse momento é importante não levantar-se na correnteza, pois pode prender o pé em uma rachadura, galhos, fendas na parte inferior do rio, ou outros, sendo assim empurrando para o fundo pela correnteza. Na questão das águas rasas, alerta sobre a natação defensiva e segura. A regra de redemoinho seguro resume-se na tentativa de não permanecer neste, para alcançar a margem. Por fim, o procedimento adequado para águas profundas, enquadra-se em nadar em direção a margem usando 0 
método rastejar, e quando nadar fique longe de perigos visando um local seguro (SILVA, 2012).

Como explorado pelos dois autores Costa (2011) e Silva (2012), os procedimentos tornam-se adequados porque podem ser executados de maneira a não problematizar, ainda mais, uma situação de risco em busca e salvamento.

\section{TÉCNICAS DE RESGATE EM ÁGUAS RÁPIDAS}

É importante destacar que muitas são as técnicas de salvamento ou resgate, inclusive no caso de águas rápidas e enchentes. Entretanto, selecionou-se o que se considera como as principais técnicas para essa espécie de salvamento.

Destaca-se ainda, que a escolha da técnica e do procedimento adequado depende de outros fatores, a se considerar. Dentre eles tem-se: características do local do evento; existência ou não de profissionais qualificados; caracterização do estado, localização e número de vítimas; também, do tipo e quantidade de material existente e disponível; condições do evento, entre outros complementos disponíveis para realizar as atividades (ARAÚJO, 2002)

Portanto, a equipe necessita além de conhecer o procedimento adequado, considerar particularidades quanto à localidade da enchente, como também, quanto aos profissionais disponíveis.

Segundo Costa (2011), as guarnições de prontidão encontrarão, em geral, vítimas isoladas pela água (parada ou corrente), seja em cima de veículos, telhados, agarradas em obstáculos como postes, telefones públicos, portões, etc. Portanto, a situação de vítima sendo conduzida pelas correntes é situação extraordinária neste tipo de resgate. 
Revista Científica do Corpo de Bombeiros Militar de Pernambuco

Seção 1 - Artigos Técnico Científicos

Artigo publicado no Vol.03 №06 - Edição de JAN a JUN 2017 - ISSN 2359-4829

Versão on-line disponível em: http://www.revistaflammae.com

Foram escolhidas entre as variadas técnicas, 10 (dez) especificamente seguidas do curso da Rescue 3 International 3 (SEGERSTROM et al. 2002) entre outras apontadas na pesquisa de Costa (2011) e Silva (2012).

\subsection{Técnica da travessia de resgate}

A travessia do resgatista é uma opção simples e rápida, necessitando de dois ou mais resgatistas, utilizando um cajado ou remo, para ter mais estabilidade e acessar a vítima (SILVA, 2012).

Todavia, antes de se entrar na água, deve-se determinar se uma travessia rasa será possível, assim, quatro fatores são examinados: profundidade, velocidade e o leito do canal. Nesse sentido, a profundidade da água se for possível determinar, será um fator limitante, já a velocidade e o leito do canal estão relacionados a uma percepção óbvia, como no caso de uma superfície extremamente plana, ou um leito com muitas pedras (SEGERSTROM et al, 2002).

Como se observa na citação anterior, essa é a técnica para se chegar até a vítima, após essa etapa, o cabo de salvamento servirá para ancorá-la ao fazer o percurso de volta.

\subsection{Técnica de resgate tipo "isca viva"}

Esse procedimento é complexo e exige habilidade, necessitando principalmente, que o resgatista saiba desenvolver a natação ofensiva. Segerstrom et al,(2002), descreve, que a técnica centra-se primeiramente em um resgatista designado, usando preferencialmente nadadeiras Churchill, esperando na margem ou no fosso de enchente, pronto para agir. Paralelamente, um ou dois resgatistas, manuseiam a corda e ficam atrás dele, 
prontos para dar segurança na margem. Quando o nadador de resgate acredita que a vítima é incapaz de fazer auto resgate ou que outra tentativa de resgate rio acima falharam, o resgate de isca viva começa. Julgando a posição da vítima, o resgatista lança-se com a cabeça na frente rio a cima em direção, devendo deixar a sua cabeça para cima para não perder de vista á vitima.

Esta é uma habilidade que precisa de muita prática, pois o resgatista com colete flutuador específico, amarrado pelas costas a um cabo entra na água contra a corrente em direção à vítima através da natação ofensiva. A oferta de linha deve ser frouxa até que o resgatista faça contato com a vítima, após os dois são rebocados por aqueles que aguardam na margem através do processo pendular.

\subsection{Técnica de resgate com bote em "v"}

Costa (2011), explica que nesse procedimento dois cabos são amarrados nos anéis laterais do bote para segurar o bote em um local na corrente acima da vítima. Assim, são necessários: um resgatista dentro da embarcação, um em cada margem e um quarto que servirá como backup abaixo da corrente com bolsa de arremesso. A técnica simples e de rápida utilização, pode ser utilizada com fortes correntezas. O bote tem que ser do tipo inflável e com fundo reto (rafting), afim de diminuir o atrito com a correnteza.

Machado (2001, p. 47), complementa alertando que "o bote será amarrado na parte externa de seus anéis laterais. Assim, depois de prender os cabos, os resgatistas irão controlar o bote levando rio acima para margem oposta". O autor salienta ainda que, cada cabo de controle deve ter pelo menos duas vezes a largura do rio, portanto a operação do sistema exige uma pessoa em cada controle para a condução do bote até a margem do rio mais favorável. Outro detalhe é de que a tripulação deve possuir facas e remo, em virtude da necessidade de terem que cortar os cabos e remar para a margem. 
Revista Científica do Corpo de Bombeiros Militar de Pernambuco

Seção 1 - Artigos Técnico Científicos

Artigo publicado no Vol.03 №06 - Edição de JAN a JUN 2017 - ISSN 2359-4829

Versão on-line disponível em: http://www.revistaflammae.com

Portanto, o controle do bote embora seja coletivo, é necessário que todos os resgatistas estejam de prontidão para a execução, para não perder 0 controle do bote em "V".

\subsection{Técnica de ancoragem da embarcação}

A ancoragem é simples e rápida, requer simplesmente de um olhar atento para que a embarcação seja ancorada, para acessar locais com dificuldade. Assim, Costa (2011), orienta que em ambiente urbano muitos locais podem servir de ponto de ancoragem, como, por exemplo, postes de luz. Logo, essa técnica requer também do domínio de fundamentos de salvamento em altura.

\subsection{Técnica "octopus"}

A "octopus" exige o domínio de técnicas de salvamento em altura como também de sistemas de forças, utilização de roldanas, além de maior entrosamento entre todos os membros da equipe. Logo, mostra-se útil quando a vítima está isolada por fortes correntezas e os resgatista com acesso aos dois lados da corrente.

Nesse contexto, é preciso montar uma técnica de travessia (tirolesa) deixando o cabo bem tencionado. Em cima da linha de sustentação, com uma roldana monta-se um sistema de "vai-vem" com uma roldana e três mosquetões. Clipa-se o bote inflável pela proa ao sistema pelo mosquetão central, que controlará a profundidade (SEGERSTROM et al, 2002).

Silva (2012) atesta que o sistema tirolesa é umas das tarefas mais difíceis que o resgatista enfrenta, porque o sistema requer mais equipamento, tempo e conhecimento para monta-lo e para conseguir executa-lo. Assim, todo este esforço é necessário para instalar uma plataforma no canal, no qual se 
Revista Científica do Corpo de Bombeiros Militar de Pernambuco

Seção 1 - Artigos Técnico Científicos

Artigo publicado no Vol.03 №06 - Edição de JAN a JUN 2017 - ISSN 2359-4829

Versão on-line disponível em: http://www.revistaflammae.com

pode trabalhar. Se tempo e pessoas suficientes estão disponíveis, esta plataforma pode ser usada para diminuir o risco para todos os envolvidos no resgate.

Para o referido autor, não é muito difícil essa instalação, mais difícil é a operação depois de estabelecido o sistema. Por isso, o trabalho de equipe é a chave para essa operação ser bem sucedida, e uma falha da equipe pode terminar em desastre. O sistema requer duas cordas através do canal, uma corda alta, a outra como a corda de controle. As cordas por sua vez, devem ser atravessadas ao mesmo tempo. O manuseio das cordas de controle deve ser realizado sem sistema de redução de carga, que impedem o manuseio do bote (SILVA, 2012).

Seguidamente, o manuseio do bote requer os sinais de apito e de mão, ou de outros sistemas técnicos. Quando usar um bote com remo central ou quando o bote é remado pela equipe, o guia dos resgatista necessita deixar o bote em uma linha com o vetor da corrente. Se isso não for feito, o bote pode virar e voltar-se, mesmo que esteja conectado ao sistema técnico. Esta tirolesa pode ser usada para - manusear o bote para uma posição no lado rio acima de uma peneira ou um veiculo, - colocar o bote rio a baixo em uma seção, quando as paredes dos dois lados forem verticais, - ou puxar um bote rio acima em direção a uma barragem ou a um refluxo (SILVA, 2012).

Segundo Costa (2011), os mosquetões laterais controlam a direção, quando um ou dois resgatista irão dentro do bote para acessar a vítima, dois controlam as laterais e um a profundidade da embarcação. A tripulação do bote deve estar preparada para cortar os cabos e remar para um local seguro em situação de emergência. Se a equipe contar com apenas três componentes, um irá à embarcação, um dará a direção de um lado da margem e outro (com o mesmo cabo) dará a outra direção e profundidade. 


\subsection{Técnica de resgate pendular com cabo}

Quando a vítima estiver isolada por fraca corrente, sem obstáculos e capaz de ajudar a si mesma, o resgatista lançará o cabo e a mesma irá seguralo acima do ombro, para que seja puxada pelos resgatistas. Entretanto se a vítima não é fisicamente capaz de se segurar no cabo, será preciso usar a técnica isca viva ou outra (SILVA, 2012).

\subsection{Técnica do uso da bolsa de arremesso}

O uso da bolsa de arremesso acontece através de seis procedimentos, onde primeiramente deve-se abrir a bolsa de arremesso e retirar alguns metros de cabo, segurando a ponta do cabo em uma das mãos e a bolsa de arremesso na outra, atendo-se em não envolver o cabo ao redor da mão ou pulso. Em seguida, a bolsa deve ser molhada, pois o peso extra acrescentará no seu alcance. Depois, é preciso estabelecer contato visual e verbal com a vítima: Grite "CORDA". Então vem o arremesso, que deve acontecer em um ponto após a vítima em virtude da correnteza, lançando em um movimento sincronizado com o deslocamento da vítima. Por fim, deve-se fazer uma boa base de sustentação do seu corpo antes de dar tensão ao cabo para que a vítima não se solte, só então segure firme a bolsa e puxe a vítima para a margem ou utilize a técnica pendular (COSTA, 2011).

Esta técnica tem como vantagem ser de rápida utilização, entretanto é fundamental que outro resgatista fique abaixo da correnteza em relação à vítima, em caso de não funcionar a técnica ou a vítima ser conduzida pelas corredeiras. 


\subsection{Técnica de resgate por linha diagonal de tensão}

A técnica de resgate por linha diagonal de tensão consiste em uma em uma linha angulada entre 45-60 graus para travessia de um ponto de risco ou para empurrar alguém sob a correnteza sem aumentar a pressão contra ela na parte superior da corrente (AMBROSI, 2010).

Conforme descreve Segerstrom et al, (2002), a linha deve estar bem estendida num ângulo diagonal á corrente e o cabo em $45^{\circ}$ da correnteza, para que não faça o deslocamento da vítima de forma transversal e sim de forma diagonal. Em correntes mais rápidas, o ângulo menor pode ser conveniente para reduzir o arrasto. O cabo esticado em diagonal pode ser utilizado de várias maneiras: para mover o resgatista através da água rasa; para resgatar remadores presos em pedras no meio do rio; como um back-up rio a baixo ou cabo de segurança.

Entretanto, quando a situação acarretar em águas profundas demais para atravessar caminhando, assim como os atravessadores nadando, Segerstrom et al (2002) alerta que a técnica preferida será usar um mosquetão com uma alça de fita tubular colocada no cabo. O resgatista simplesmente segura-se com a mão oposta a direção a qual ira se mexer, vira-se de costas (de barriga para cima) e aponta seus pés rio a baixo. Quando levar uma vítima, o método ideal será colocar o mosquetão "rabo de vaca" ("cow-tail") do salvavidas de resgate na corda. Assim o resgatista poderá segurar a vitima com suas duas mãos e deixar que a corrente os leve ao outro lado. 


\subsection{Técnica de resgate de pessoas em veículos presos em águas correntes}

Essa técnica de resgate de pessoas presas em veículos, pode ser usada além de situações de enchentes, pois, num acidente automobilístico um veículo fora de controle pode facilmente cair em um rio. Mesmo, em inundações é comum veículos ficarem presos pala água, deixando ilhados seus ocupantes (ARAUJO, 2002).

Segundo Silva (2011), um fator muito importante neste tipo de resgate é verificar o tipo de solo em que se encontra o veículo (asfalto, concreto, lama, areia, etc.). Nesse sentido, em uma superfície dura é mais instável (podendo o carro escorregar ou deslizar com a força da água), já em superfícies moles o carro frequentemente afunda tornando o veículo mais estável.

Após a chegada no local e o gerenciamento dos riscos, deve-se acessar o veículo, utilizando a técnica "isca viva", Octopus ou condução de embarcação inflável. Em caso de se utilizar a técnica "isca viva ou a condução de embarcação, é fundamental o aproveitamento da área de remanso proporcionada pelo próprio veículo". Em seguida, o veículo precisar ser estabilizado, prendendo-o às cordas para mantê-lo estável, assim se necessário quebre os vidros para acessar as vítimas e forneça coletes salvavidas para os ocupantes. Por fim, o profissional deve estabeleça prioridades entre as vítimas e transporta-las utilizando a técnica escolhida até um local seguro (MACHADO, 2001).

Compreende-se que as técnicas de resgate em águas rápidas, entrelaçam-se conforme a intensidade de riscos em que se encontram as vítimas, podendo uma técnica favorecer ou facilitar o procedimento de outra, e assim gradativamente (SEGERSTROM, 2002). 


\subsection{Técnica de condução de bote inflável a remo}

Essa técnica pode ser uma das mais utilizadas em enchentes, para transitar em áreas alagadas, para que a equipe acesse a vítima remando até o local, isso demanda planejamento e treinamento da guarnição (AMBROSI, 2010; SEGERSTROM, 2002).

Costa (2011) aponta que se deve prever, desde como será organizada a equipe, até questões de incidentes, como em caso de um resgatista cair na água, ou distribuição de peso no bote, entre outras questões. Parafraseando suas orientações, listou-se algumas particularidades desta orientação:

a) Organização da equipe de salvamento: inicialmente necessita-se da determinação de um guia, responsável pela segurança de todos os integrantes e do deslocamento do bote. Esse guia deve ser o integrante mais experiente em águas rápidas, estabelecido pelo comandante da equipe. Assim, todas as ações no bote serão desenvolvidas somente com o comando do guia, por exemplo, a distribuição do peso do bote da melhor maneira possível (bote inflável de 12 pés $(6,5 \mathrm{~m})$ pode ser utilizado de 2 a 7 pessoas). Uma guarnição de resgate deverá ser composta de 1 guia e 2 ou 3 resgatistas. Além de outras particularidades de organização da guarnição segundo o autor referido.

b) A remada: os integrantes da equipe de resgate deverão estar sentados na lateral da embarcação com o tronco voltado para frente, na posição corporal que sinta melhor equilíbrio e sempre segurando o "pega-mão" do remo. Segura-se o remo com ambas mãos, braço estendido para a remada, esta deve ser coordenada e simultânea entre as posições 2 e 3, acompanhado pelas posições 4,5 e 6 . O guia tem a função de direcionar, como leme da embarcação. Só se inicia e interrompe a remada através dos comandos de remada do guia. São comandos da remada:

- A frente = todos a frente coordenadamente; 
- A ré = todos a ré, não necessita coordenar esta ação;

- Direita a ré = os do lado esquerdo rema a ré, enquanto da direita remam a frente;

- Esquerda a ré = os do lado esquerdo rema a ré, enquanto da direita remam a frente;

- Alto = todos param de remar, tiram os remos da água e seguram-no no colo;

- Piso = todos seguram o remo e sentam na parte interna do bote.

c) Formas de guiada: o curso das corredeiras, obstáculos e a força da equipe requerem certas remadas da equipe e do condutor, para posicionar o bote, manter ou mudar a posição da embarcação.

Costa (2011) salienta que o guia deve manter os remos na água o máximo de tempo possível, devendo fazer o leme da embarcação para evitar a instabilidade do bote. Preferencialmente, o guia deve ordenar aos integrantes os comandos mais simples como a frente e a ré. Se necessário mudança de direção do bote, deve se antecipar as necessidades e utilizar seu próprio remo para mudar o rumo. Por fim, o guia deve explicar antes à equipe os planos de acesso à vítima, a durante o trajeto dar o apoio mental quando a equipe necessitar.

d) Acessar a vítima: preferencialmente, a equipe deve aproximar-se da vítima com a lateral do lado do guia do bote, atendendo a distribuição de peso da embarcação, assim, a abordagem e retirada da vítima da água deverá ser feita por apenas de um resgatista, pois o bote inflável pode virar caso outro resgatista venha a ajudar. Portanto, enquanto o resgatista puxa a vítima para dentro da embarcação, os outros dois mantém a direção e a estabilidade.

e) Comportamento ao cair do bote: caso um integrante caia sozinho do bote durante o deslocamento na água, a tendência é ele ser "arrastado" para o fundo do bote. Logo, um comportamento normal nesta situação em botes com o fundo plano é empurrar o fundo do bote, em busca de recuperação. Deve ser orientado antes da operação que se houver uma queda na água deve-se tatear 
o fundo em busca das laterais da embarcação. Se o integrante não for para o fundo da embarcação e permanecer no leito do rio deverá manter o corpo na posição horizontal com os pés voltados para frente, fazendo leme com as mãos, então deve ir para a margem ou procurar um remanso e aguardar também o resgate.

f) Comportamento se o bote virar: se a embarcação virar $180^{\circ}$ sobre seu eixo, há duas possibilidades: Primeira: o integrante será "lançado pelo ar" e poderá cair na água, pedras, até mesmo na margem. Segunda: o integrante segurará na corda lateral do bote e ficará preso embaixo do bote, em um compartimento que possui ar limitado. Neste caso, é importante manter a calma, procurar com as mãos a parte externa do bote acima da linha d'água. Então mergulhar em direção pra fora do bote, mantendo as mãos naquela parte do bote.

h) Acessar o bote pela água: A tendência natural de qualquer pessoas que pela água segurar no bote é ter as pernas "arrastadas" para o fundo da embarcação. Nesta maneira, é muito difícil subir. Portanto, deve manter o corpo o mais horizontal possível, braços estendidos segurando na corda lateral. Nesta posição deve-se dar um impulso forte, não soltando a corda, e por fim, quando a cintura já estiver acima das bóias laterais, deixar cair o peso do corpo para o fundo da embarcação.

Enfim, dessas 10 (dez) técnicas descritas, é perceptível que na teoria há uma gama complexa de interpretação, porém na prática a situação de dificuldade intensifica-se. É na prática, no preparo e na formação contínua que a dicotomia entre teoria e prática é superada.

\section{METODOLOGIA}

O artigo foi desenvolvido por meio de uma pesquisa qualitativadescritiva, onde foi aplicado um questionário investigativo para verificar a 
Revista Científica do Corpo de Bombeiros Militar de Pernambuco

Seção 1 - Artigos Técnico Científicos

Artigo publicado no Vol.03 №06 - Edição de JAN a JUN 2017 - ISSN 2359-4829

Versão on-line disponível em: http://www.revistaflammae.com

percepção dos bombeiros quanto a formação específica no resgate em águas correntes e enchentes.

Atendo-se na coleta e análise dos dados, optou-se pela pesquisa qualitativa-descritiva, a qual segundo Minayo (2000), busca responder a questões muito particulares, trabalhando com um universo de significados, valores e atitudes visando compreender a realidade de determinado grupo social.

Para Santos (1999), uma pesquisa é descritiva, por buscar levantar dados a partir de um problema ou fenômeno em estudo, assim, os dados são observados, registrados, analisados e interpretados. Portanto, o estudo descritivo procura abranger aspectos gerais e amplos de um contexto social.

Nesse contexto, à pesquisa qualitativa-descritiva foi desenvolvida a partir de um questionário aplicado ao público-alvo da pesquisa, bombeiros do Paraná, alunos do Curso de Formação de Sargentos, do Centro de Ensino e Instrução do Corpo de Bombeiros Militares da Polícia Militar do Paraná, 2014.

O questionário aplicado (Anexo A), foi composto por 5 (cinco) questões alternativas, as quais foram respondidas por 75 (setenta e cinco) bombeiros alunos do curso de formação para sargentos. A aplicação do questionário visou investigar a concepção dos bombeiros do Paraná, quanto ao resgate em águas correntes, juntamente ao preparo e formação desses profissionais para atuarem nesse tipo de salvamento. Na sequência, tem-se a exploração dos resultados obtidos com o questionário e os devidos comentários elaborados a partir de subsídios teóricos.

\section{RESULTADOS E DISCUSSÕES}

Considerando os sujeitos alvo da pesquisa, e as realidades enfrentadas por esse profissional, a primeira pergunta, visava observar se os bombeiros possuíam curso de Guarda-Vidas, pois é uma formação importante 
para o resgate em águas rápidas e enchentes. $\mathrm{O}$ resultado das respostas obtidas pode ser verificado no Quadro 1 a seguir:

\section{Quadro 1. Você possui o curso de Guarda-Vidas?}

\begin{tabular}{|c|c|}
\hline Sim & Não \\
\hline $52 \%$ & $48 \%$ \\
\hline
\end{tabular}

Fonte: Os autores (2014).

Compreende-se através da tabela que dos 75 (setenta e cinco) bombeiros que responderam o questionário, mais da metade já possui o curso de Guarda-vidas, o que é fundamental para a atuação em uma equipe de resgates em águas correntes e enchentes, pois há técnicas que exigem capacidades que são estimuladas e aperfeiçoadas a partir da formação em Guarda-vidas.

Outra questão importante a se considerar, está relacionada ao tempo de experiência, o que nem sempre é sinônimo de preparação profissional para atuar como resgatista. Assim, verificou-se que dos bombeiros do Paraná, que estão fazendo o Curso de Sargentos, 23 (30\%) atua como bombeiro a mais de 20 (vinte) anos, enquanto $42(56 \%)$ atua a mais de 10 (dez) anos e apenas 10 (13\%) atua a menos de 10 (dez) anos, como observa-se no Quadro 2.

Quadro 2. A quanto tempo trabalha no corpo de bombeiros?

\begin{tabular}{|c|c|c|}
\hline Menos de $\mathbf{1 0}$ anos & Mais de $\mathbf{1 0}$ anos & Acima de $\mathbf{2 0}$ anos \\
\hline $13 \%$ & $56 \%$ & $30 \%$ \\
\hline
\end{tabular}

Entretanto, na questão seguinte verificou-se uma lacuna na formação profissional, onde dos 75 (setenta e cinco) bombeiros, 66 (sessenta e seis) (88\%), não fizeram ou tiveram curso de treinamento para resgatista em águas correntes e enchentes. 
Quadro 3. Na sua preparação para a formação no Corpo de Bombeiros, teve o curso de treinamento referente a resgates em Água corrente e enchentes?

\begin{tabular}{|c|c|}
\hline Sim & Não \\
\hline $12 \%$ & $88 \%$ \\
\hline
\end{tabular}

Fonte: Os autores (2014).

A quantidade de 9 (nove), ou seja, 12\% dos bombeiros apenas, tiveram essa formação específica. Percebe-se um percentual pequeno, diante da frequência com que as enchentes têm ocorrido principalmente em casos de desastres naturais que acabam colocando boa parte da população em situações de risco.

A antiga tradição de tentar um resgate descuidando do risco pessoal tem sido modificada com o tempo e com o aumento da complexidade dos resgates em geral e como o resgate de água, particularmente. Dessa forma, não serve de grande conforto falar que um resgatista morreu tentando ajudar alguém, em vez disso, resgatistas profissionais concordam que é preferível voltar do incidente, mesmo que a vítima não volte com ele, ou esteja a salvo (SEGERSTROM, 2002).

Percebe-se que a formação específica para esse tipo de resgate, como a compreensão de suas particularidades e a experiência nessas situações, são fundamentais principalmente na questão de análise risco/benefício, uma vez que, o salvamento só é efetuado após a percepção clara dos perigos e quando se tem a visão do que é necessário para o resgate. Lembrando, que a tarefa final do resgatista, é retornar para casa no fim do seu trabalho.

Complementando a análise do conhecimento dos bombeiros do Paraná, quanto a esse tipo de resgate, buscou-se pesquisar se em algum outro curso de formação, anterior ao de Sargento, estes tiveram alguma disciplina que envolvesse informações sobre 0 resgate em águas correntes ou enchentes, Quadro 4. 
Quadro 4. Na preparação de cursos anteriores ao de Sargento do Corpo de Bombeiros, você teve alguma disciplina relacionada à salvamento, resgate em águas correntes e enchentes?

\begin{tabular}{|c|c|}
\hline Sim & Não \\
\hline $20 \%$ & $80 \%$ \\
\hline
\end{tabular}

Fonte: Os autores (2014).

Novamente, conforme está representado no Quadro 4, 60 (sessenta) bombeiros, que representam os $80 \%$, não têm conhecimento específico, teórico, nem prático quanto as particularidades do resgate em águas correntes e enchentes. Portanto, poucos têm conhecimentos sobre as técnicas de resgate, ou ainda possuem informações superficiais.

Conforme Segerstrom (2002, p. 40), "pessoas que não tenham esse tipo de treinamento podem ajudar, mas não em situações em que haja o perigo de caírem na água". Logo, são requeridas muitas vezes, habilidades especiais para uma busca em água corrente, pois, resgatistas usando embarcações, botes e pranchas de resgate, são preferíveis, porém este tipo de equipamento requer alto nível de treinamento, como também competência.

Destaca-se que os procedimentos adequados para a execução das principais técnicas de resgate em enchente ou águas correntes, são complexos e exigem capacidade, treinamento e habilidades especiais. Sendo muito importante, portanto a conscientização dessas especificidades, em cursos de formação continuada, preparando os resgatistas.

Assim, a ultima pergunta do questionário visou verificar a opinião dos bombeiros do Paraná, quanto a importância da formação continuada e o treinamento sobre resgates em águas correntes e enchentes: Quadro 5. 
Quadro 5. É importante que os profissionais do Corpo de Bombeiros, recebam cursos de formação e treinamento continuado sobre resgates em águas correntes e enchentes?

\begin{tabular}{|c|c|c|}
\hline $\operatorname{Sim}$ & Talvez & Não \\
\hline $94 \%$ & $5,3 \%$ & 0 \\
\hline
\end{tabular}

Fonte: Os autores (2014).

Como pode se observar no Quadro 5, 71 (setenta e um) dos bombeiros, o que representa (94\%), apontaram que sim, é importante que se tenha essa preparação especificamente para os resgates e salvamentos em águas correntes e enchentes.

A especialização profissional é destacada por Tibery (1976, p.63) como uma "energia proveniente dos recursos humanos [...] fundamental para enfrentar emergências, especialistas não podem ser improvisados, são necessários verdadeiros conhecimentos técnicos e práticos sobre vários serviços inerentes às atividades de defesa civil' (TIBEY, 1976, p. 63). Certamente os problemas a serem enfrentados diante de um desastre exigem um perfeito conhecimento das operações e formação profissional específica do resgatista.

Conforme discutido anteriormente neste artigo, um resgatista é treinado para ter em mente que, quando está prestando socorro, sua segurança vem em primeiro lugar, seguida da segurança da equipe, e por fim da vítima. Embora esse pensamento, pareça contraditório, é centrado a partir do básico de não gerar novas vítimas. Enfim, a eficiência de um resgate ou o número de vidas a serem salvas, depende muito da prontidão da equipe e do modo como os fatos são desencadeados.

Segerstrom et al, (2002, p. 39) alerta ainda que, "a disponibilidade de resgatistas treinados deveriam trabalhar dentro da água ou dentro da área de $3 m$ da margem". Logo o pessoal adequado precisa estar disponível, um grande resgatistas poderia ser necessário, mesmo para buscar somente uma vitima. Por exemplo, no caso em que um bote vire, é possível que varias buscas 
Revista Científica do Corpo de Bombeiros Militar de Pernambuco

Seção 1 - Artigos Técnico Científicos

Artigo publicado no Vol.03 №06 - Edição de JAN a JUN 2017 - ISSN 2359-4829

Versão on-line disponível em: http://www.revistaflammae.com

tenham que ser iniciadas, cada uma requerendo resgatistas treinados. Pessoas que não tenham esse tipo de treinamento podem ajudar, mas não em situações em que haja o perigo de caírem na água.

Segundo, Ramos et al (2011), existem poucas equipes realmente treinadas e preparadas para este tipo de ocorrência e somente com uma boa formação e treinamento, será alcançada uma atuação mais segura ao socorrista e a vítima em uma situação de risco.

Enfim, existem muitos pontos nos deveres relacionados ao resgate de águas correntes, como as normas de treinamento, políticas operacionais, diretivas de segurança, técnicas de resgate, qualificações dos profissionais e resgate, entre outros pontos relevantes. É nesse aglomerado de teorias, técnicas e práticas que é desenvolvido um programa completo de resgate em águas rápidas e enchentes.

\section{CONCLUSÕES}

Atualmente o mundo sofre com o grande aumento de desastres naturais, que atingem geralmente um grande número de vítimas. E conforme demonstrado na fundamentação teórica e na pesquisa de campo, muitos dos bombeiros encontram-se com pouco conhecimento, ou preparo e treinamento superficial para socorrer ou planejar uma ação de busca e salvamento.

Além do despreparo profissional, outros fatores necessitam de maior atenção dos órgãos superiores, como materiais e equipamentos disponíveis, equipes específicas para esse resgate, compreensão das particularidades das regiões onde há enchentes reincidentes, entre outros.

Compreende-se que as particularidades do resgate em estudo, são mais complexas do que se imagina, pois somente com um estudo mais aprofundado, é possível ampliar o conhecimento e tomar consciência de que o resgate técnico cresce dinamicamente, pois os recursos e tecnologias estão crescendo, mas os problemas ambientais crescem ainda mais rápido. 
Revista Científica do Corpo de Bombeiros Militar de Pernambuco

Seção 1 - Artigos Técnico Científicos

Artigo publicado no Vol.03 №06 - Edição de JAN a JUN 2017 - ISSN 2359-4829

Versão on-line disponível em: http://www.revistaflammae.com

Observa-se por fim, a necessidade da oferta de cursos correlacionados com as técnicas de salvamento em águas rápidas, como por exemplo, o curso de guarda-vida, o que contribuiria para uma formação mais segura para futuras eventualidades em águas rápidas.

É perceptível, portanto, a conscientização dos bombeiros do Paraná quanto à importância da complexidade e da necessidade de cursos de formação continuada sobre as técnicas já existentes para o resgate em estudo, também o tipo ideal de embarcação, bem como estudo de casos de resgate em águas rápidas em futuros eventos de desastres naturais, até por questão de previsibilidade.

Uma vez que, as técnicas apresentadas no decorrer dessa pesquisa, nem de longe esgotam todas as técnicas possíveis para o resgate em enchentes. Assim, é clara a necessidade de estudos complementares do tema, bem como a criação de um banco de dados, para melhor acesso a esses materiais/manuais técnicos, além da formação de especialistas na área, para que assim, consequentemente, sejam executados cada vez mais as buscas e salvamentos em águas rápidas com sucesso e com 0 número significativamente reduzido de vítimas.

\section{REFERÊNCIAS}

ALVES, Nágila Cristina et al. Receita orçamentária: uma análise comparativa entre os sete municípios do litoral do Paraná. F. Ciências Sociais Aplicadas 3. Economia - 6. Economia Monetária e Fiscal. Disponível em: < http://www.sbpcnet.org.br/livro/64ra/resumos/resumos/2805.htm>. Acesso em: 28 ago. 2014.

AMBROSI, Andrei. Meio de resgate para uso em enchentes na cidade de Blumenau. Fundação Universidade Regional de Blumenau. Blumenau, 2010. (Trabalho de Conclusão de Curso). Disponível em: <http://www.bc.furb.br/docs/mo/2011/345300_1_1.pdf>. Acesso em: 30 ago. 2014. 
ANGULO, Rodolfo J. As praias do Paraná: problemas decorrentes de uma ocupação inadequada. R. Paran. Desenv. Curitiba, n. 99, p. 97-103, jul./dez. 2000. Disponível em: http://www.ipardes.pr.gov.br/ojs/index.php/revistaparanaense/article/view/238/1 96>. Acesso em: 16 ago. 2014.

ARAÚJO, Francisco B. Manual de instruções técnico profissional para bombeiros. Distrito Federal: Corpo de Bombeiros Militar do DF, [2002]. Disponível em www.cbmdf.gov.br . Acesso em: 15 set. 2014.

CARTA HUMANITÁRIA. 2004. Disponível em: <http://www.sphereproject.org/portugues/ handbook/ch-p.pdf>. Acesso em: 2 set. 2009.

CASTRO, Antônio Luiz Coimbra de. Manual de planejamento em defesa civil. 1. ed. Brasília: Ministério da Integração Nacional Secretaria de Defesa Civil, 1999. v.1.

CORPO DE BOMBEIROS MILITAR DE SANTA CATARINA. Manual de Salvamento Aquático: Curso de Formação de Guarda-Vidas Militar. Florianópolis: $\quad$ CBMSC, $2010 . \quad$ Disponível em:< http://biblioteca.cbm.sc.gov.br/biblioteca/images/stories/CBM/apostilas/CFGVM. pdf>. Acesso em: 10 set. 2014.

CORPO DE BOMBEIROS DA POLÍCIA MILITAR DE SÃO PAULO. Manual de Salvamento em Enchentes. São Paulo. CBPMESP 2006 (Manuais Técnicos de Bombeiros, 10).

COSTA, Guilherme Viríssimo da S. Técnicas de resgate em inundações. Biblioteca CBM/SC. Florianópolis, 2011. (Monografia). Disponível em: < http://biblioteca.cbm.sc.gov.br/biblioteca/dmdocuments/CFO_2011_Guilherme. pdf>. Acesso em: 16 ago. 2014.

MACHADO, Renaldo Manoel. Atividades preventivas e de Salvamento Aquático em água doce. Monografia Curso de Especialização para Bombeiros Oficiais. Florianópolis, 2001.

MINAYO, M. C.de S. et al. Pesquisa Social: Teoria, método e criatividade. 16. ed. Petrópolis: Ed. Vozes, 2000.

RAMOS, Wellington et al. As enchentes no contexto dos desastres naturais. VI Encontro Nacional e IV Encontro Latino-americano sobre Edificações e Comunidades Sustentáveis - Vitória - ES - BRASIL - 7 a 9 de setembro de 
2011. Disponível em: < http://www.elecs2013.ufpr.br/wpcontent/uploads/anais/2011/2011_artigo_030.pdf>. Acesso em: 16 ago. 2014.

SANTOS, Antônio Raimundo dos. Metodologia científica: a construção do conhecimento. Rio de Janeiro: DP \& A, 1999.

SCHONËR, Thomas. Água Selvagem: Condução de embarcações infláveis a remo. [s.n.] Manual. [2011?] 52p.

SEGERSTROM, Jim. et al. Swiftwater Rescue Technician Advanced Manual. Tradução: Thomas Schoner e Andreia Schoner. Rescue 3 International. Wilton, Califórnia. Rescu. 2002.

SILVA, Laionel da. Técnicas de salvamento em águas rápidas. Curso de Formação de Soldados. Biblioteca CEBM/SC, Florianópolis, 2012. Disponível em:< file:///C:/Users//Downloads/CFSd_2012_1_Laionel\%20(2).pdf>. Acesso em: 16 ago. 2014. 


\begin{abstract}
ANEXO A
CENTRO DE ENSINO E INSTRUÇÃO DO CORPO DE BOMBEIROS MILITARES DA POLÍCIA MILITAR DO PARANÁ - CURSO DE FORMAÇÃO DE SARGENTOS BOMBEIRO MILITAR - 2014

*Esse questionário é parte integrante de uma pesquisa científica, os resultados serão discutidos num artigo científico, apresentado ao curso de formação de sargentos.

1. Você possui o curso de Guarda-Vidas?

( ) $\operatorname{sim}($ ) não ( ) gostaria de ter

2. A quanto tempo trabalha no CBM?

( ) menos de 4 anos ( ) mais de 4 anos ( ) acima de 10 anos

3. Na sua preparação para a formação no CBM, teve o curso ou treinamento referente a resgates em Água Corrente e enchentes?

( ) sim ( ) não

4. Na preparação de cursos anteriores ao de Sargento do CBM/PR, você teve alguma disciplina relacionada à salvamento, resgate em águas bravas ou enchentes?

( ) $\operatorname{sim}($ ) não

5. É importante que os profissionais do CBM/PR, recebam cursos de formação e treinamento continuado sobre resgates em águas correntes e enchentes?

() $\operatorname{sim}()$ talvez ( ) não
\end{abstract}

